\title{
The Early Response to the Coronavirus-Surveys in Southern Texas
}

\author{
Meng Zhao ${ }^{1}$, Laura Monahan ${ }^{1}$, Michael Monahan ${ }^{1}$, Yuxia Huang ${ }^{2} \&$ Sunil Mathur $^{2}$ \\ ${ }^{1}$ College of Nursing \& Health Sciences, Texas A\&M University, Corpus Christi, U.S.A. \\ ${ }^{2}$ College of Science \& Engineering, Texas A\&M University, Corpus Christi, U.S.A. \\ Correspondence: Meng Zhao, College of Nursing \& Health Sciences, Texas A\&M University, Corpus Christi, TX, \\ 78414, USA. Tel: 1-361-825-3279.
}

Received: July 6, 2021 Accepted: August 31, 2021 Online Published: September 8, 2021

doi:10.5539/gjhs.v13n10p75

URL: https://doi.org/10.5539/gjhs.v13n10p75

\begin{abstract}
The objective of this study was to investigate if Southern Texas communities were prepared in their awareness and knowledge of the coronavirus disease 2019 (COVID-19) in timed snapshots as the pandemic unfolded. Two assessment surveys were implemented utilizing the Coronavirus Awareness and Preparedness Scale (CAPS) in March and April 2020, respectively. A convenience sample of university faculty in Southern Texas was used. Responses to survey questions changed significantly in the one-month timeframe. Respondents' perception of the COVID-19 threat increased dramatically from March to April, while their perceived preparedness facing the COVID-19 also increased tremendously. The recognized benefits of mask-wearing were limited in both March and April. Males and older people aged 55 and above had significantly lower awareness of the COVID-19 in March $(p<0.05)$ and may need more attention at the early phases of a pandemic. The increased availability of COVID-19 information through public health agencies led to the increased awareness of COVID-19. When facing a pandemic, both healthcare education and health care policy approaches are essential in addressing the containment and the eradication of COVID-19.
\end{abstract}

Keywords: Pandemic, COVID-19, awareness

\section{Introduction}

By March 2020, the coronavirus disease 2019 (COVID-19) caused by a novel coronavirus, the SARS-CoV-2, resulted in over 200 million infections and 4 million deaths (World Health Organization [WHO], 2021). After its first outbreak in Wuhan, China, in December 2019, COVID-19 spread worldwide and in the United States (CDC, 2020). On January 30, 2020, the World Health Organization (WHO) declared the COVID-19 a Public Health Emergency. Soon, New York's Governor Andrew Cuomo declared a State Disaster Emergency, closing bars, restaurants, cinemas, and public gatherings in New York (Cuomo, 2020). On March 13, 2020, President Trump officially declared the National State of Emergency, and multiple states then declared increased restrictions and stay-at-home orders (Facher, 2020).

From March to April 2020, 42 states in the United States were in lockdown, encompassing 306 million people, or 95\% of the United States' population (USA Today, 2020). Experts predicted that national semi-voluntary lockdowns and intensive social distancing could last for months or even longer (Branswell, 2020). In mid-April 2020, sixteen million Americans applied for unemployment, and the Economic Policy Institute had estimated that unemployment in the United States could reach $16 \%$ by July 2020 (higher than any point since the Great Depression), a dramatic increase from the multi-decade low of 3.5\% in February 2020 (Stebbens, 2020, April 18). In late April 2020, there were 22,530,000 confirmed cases and 153,631 deaths from COVID-19 in 177 countries across the world (The New York Times, 2020, April 18a). In the United States during that same time, there were 717,825 confirmed cases and 34,022 deaths from COVID-19 (The New York Times, 2020, April 18b). Forecasting the end of the COVID-19 date had been problematic when the pandemic just unfolded. Harvard University researchers have predicted, based on estimates of seasonality, immunity, and cross-immunity, that recurrent outbreaks of COVID-19 would occur and that "intermittent distancing may be required into 2022 unless critical care capacity is increased substantially, or a treatment or vaccine becomes available" (Stieb, 2020, April 14).

At the time when there was no effective cure for the COVID-19 and no vaccines available, it became crucial to know if communities were adequately prepared in their awareness of the COVID-19 threat, their knowledge for adequate infection control, and their confidence levels in their perception of society's preparedness to keep the COVID-19 under control. As the COVID-19 virus was highly contagious, public precautions and prevention were 
crucial to control and constrain the spread of the COVID-19, a potentially deadly disease. In response, the CDC (2020) had published a variety of guidelines to support healthcare professionals, public health agencies, and communities in coronavirus infection control. Health education of these precautions can prepare the public to keep the COVID-19 under control, while health policy may play a more vital role in stopping the transmission of the COVID-19. Without the benefit of hindsight, it was difficult to discern which health lever result would be more effective amid a chaotic pandemic. However, the biases and predilections of a community uncovered by the COVID-19 preparedness survey could guide public health officials' insight into which lever may be more optimal at various phases of a multi-year pandemic. A Coronavirus Awareness Preparedness Scale (CAPS) was developed specifically for this study to answer two questions: (a) How did the community in southern Texas perceive the coronavirus, including its threat, precautions, preparedness, and information accuracy? (b) Were there any differences in awareness and preparedness of the COVID-19 between March and April 2020? The objective is to investigate if Southern Texas communities were prepared in their awareness and knowledge of the COVID-19 in timed snapshots during March and April as the pandemic unfolded.

\section{Method}

\subsection{Design}

A non-experimental, longitudinal design was used in this study. The CAPS was developed to investigate faculty's preparedness and awareness in response to COVID-19 at a southern Texas university.

\subsection{Sample and Procedure}

In response to the rapid increase in coronavirus cases in the United States in early 2020, the first CAPS survey was expeditely implemented in March 2020. The second CAPS survey was distributed in April 2020. Through convenience sampling, both samples were recruited from a potential pool of 457 faculty who worked at a southern Texas university. The same survey was distributed to both convenience samples. A recruitment email with the study information sheet was sent through the university's faculty email list upon receipt of Institutional Review Board (IRB) approval.

A Qualtrics link with a QR code was supplied to those who wished to participate in the study. The surveys requested no personal identifying information. The data collected included anonymized demographic information on age group, gender, ethnicity, and education. The CAPS survey took participants approximately 5 to 10 minutes to complete online. A total of 104 and 75 completed surveys were received in March and April, respectively.

\subsection{Measurement}

The CAPS developed for this study had a total of 51 questions, which were grouped into four subscales: the perceived threat of the coronavirus, the perceived precautions for the coronavirus, the perceived preparedness for coronavirus control, and the perceived accuracy of receiving information. Most questions were constructed in a Likert-scale format where respondents indicated their level of agreement, threat, or confidence with each statement. A minimum rating of " 1 " indicated the strongest disagreement or least threat/confidence, a maximum rating of " 5 " indicated the strongest agreement or highest threat, and a maximum of "7" indicated the strongest confidence. The other items were answered by "yes," "no," or "don't know." All the ratings were summed to get the ratings for each subscale and then the overall scale was obtained by summing the ratings of all four subscales. Sample items for each subscale are shown in Table 1.

Table 1. Sample Items of Each Subscale in CAPS

\begin{tabular}{ll}
\hline Subscales & Items \\
\hline Perceived Threat & What level of threat do you think the coronavirus poses to your family? \\
& $\square$ Very High $\square$ High $\square$ Moderate $\square$ Low $\square$ Very Low \\
\hline & Do you avoid touching your eyes, nose, and mouth so as not to contract the \\
& coronavirus? \\
& $\square$ Yes $\square$ No $\quad \square$ Don’t Know \\
Perceived Precautions & Do you avoid large crowds of people so as not to contract the coronavirus? \\
& $\square$ Yes $\square$ No $\quad \square$ Don’t Know \\
\hline
\end{tabular}


Based on what you have seen, read, or heard, how confident are you that Healthcare Professionals in your country are prepared and can effectively deal with the

Perceived Preparedness coronavirus?

$\square$ Very Confident $\square$ Confident $\square$ Somewhat Confident $\square$ Neutral $\square$ Somewhat Unconfident $\quad$ Unconfident $\quad$ Very Unconfident

Do you agree or disagree with the following: The media has exaggerated the extent of

Perceived Information Accuracy the coronavirus outbreak?

$\square$ Strongly Agree $\quad \square$ Agree $\quad \square$ Neutral $\quad \square$ Disagree $\quad \square$ Strongly Disagree

\subsection{Data Analysis}

The descriptive statistics were used to delineate the demographics and compare the March and April surveys. Pearson's Chi-Square Test was used to examine whether there was a significant difference between the March and April surveys regarding the perceived threat, precautions, preparedness, and information accuracy. Furthermore, the differences between gender and age groups in March and April surveys were also examined using Pearson's Chi-Square Test. All the statistical tests were run at the significance level of $\mathrm{p}<0.05$ using Python.

\section{Results}

\subsection{Results of Descriptive Statistics}

A total of 104 people responded to the March survey, and a total of 75 responded to the April survey. Their demographics are shown in Table 2.

Table 2. Demographics in March and April

\begin{tabular}{llcccc}
\hline & & \multicolumn{2}{c}{ March } & \multicolumn{2}{c}{ April } \\
\cline { 3 - 6 } & & $\mathrm{N}(=104)$ & $\%$ & $\mathrm{~N}(=75)$ & $\%$ \\
\hline Age & $<34$ & 12 & 11.6 & 7 & 9.4 \\
& $35-44$ & 28 & 26.9 & 18 & 24.0 \\
& $45-54$ & 18 & 17.3 & 16 & 21.3 \\
& $55-64$ & 34 & 32.7 & 25 & 33.3 \\
& $>65$ & 12 & 11.5 & 9 & 12.0 \\
\hline \multirow{2}{*}{ Gender } & Female & 63 & 60.6 & 42 & 56.8 \\
& Male & 38 & 36.5 & 31 & 41.9 \\
& Prefer not to say & 3 & 2.9 & 1 & 1.3 \\
\hline Ethnicity & White & 86 & 83.5 & 58 & 77.3 \\
& Non-White & 15 & 14.6 & 16 & 21.4 \\
& Missing & 2 & 1.9 & 1 & 1.3 \\
\hline Education & Master's degree & 25 & 24.0 & 48 & 34.7 \\
& Doctorate & 78 & 75.0 & 26 & 64.0 \\
& Others & 1 & 1.0 & 1 & 1.3 \\
\hline
\end{tabular}

The responses to the overall CAPS surveys and each of the four subscales had changed dramatically in a one-month period. As shown in Table 3, perceived threat and perceived preparedness tremendously increased while perceived precautions and perceived information accuracy substantially decreased. The responses to most of the scale items also changed dramatically. For example, in the sample item of the subscale "Perceived Threat", "What level of threat do you think the coronavirus poses to your family", 1.9\% of participants responded "very high threat," and 7.7\% responded "high threat" in the March survey, while the percentages jumped to $16 \%$ and $32 \%$, respectively, in the April survey. For the sample item of the subscale "Perceived Precautions," "Do you avoid large crowds of people so as not to contract the coronavirus," there were $35 \%$ of respondents that chose "Yes" in the March survey, while $94.5 \%$ chose "Yes" in the April survey. For the question of "Based on what you have seen, 
read, or heard, how confident are you that healthcare professionals in your country are prepared and can effectively deal with the coronavirus," an item of "Perceived Preparedness," 6.7\% of the responses were "very unconfident" and $17.3 \%$ were "confident" in the March survey, while the percentages increased to $14.6 \%$ and $28 \%$ respectively in the April survey. For the question of "Do you agree or disagree with the following: "The media has exaggerated the extent of the coronavirus outbreak?", a sample item of the subscale "Perceived Information Accuracy," 17\% responses were "Strongly Agree," and 25\% were "Agree" in the March survey, while the percentages dropped to $6.7 \%$ and $17.3 \%$, respectively, in the April survey.

Table 3. Responses to the CAPS Survey

\begin{tabular}{lrrrr}
\hline & \multicolumn{2}{c}{ March } & \multicolumn{2}{c}{ April } \\
\cline { 2 - 5 } & Mean & SD & Mean & SD \\
\hline Overall Rating & 81.63 & 19.72 & 82.06 & 17.78 \\
Perceived Threat & 10.17 & 3.25 & 15.04 & 3.01 \\
Perceived Precautions & 25.83 & 3.65 & 24.97 & 3.40 \\
Perceived Preparedness & 18.47 & 5.09 & 21.57 & 4.77 \\
Perceived Information Accuracy & 27.16 & 7.73 & 20.48 & 6.60 \\
\hline
\end{tabular}

\subsection{Results of Chi-Square Two Sample Tests}

The Chi-Square two-sample tests were conducted to examine the differences between the results from the March survey and the April survey. The tests' results showed a significant association between people's time conducting the surveys and their perceived threat, precautions, preparedness, and information accuracy, $X^{2}(3, \mathrm{~N} 1=104$, $\mathrm{N} 2=75)=186, \mathrm{p}<.05$.

The Chi-Square two sample tests' results also indicated a significant difference in two age groups, namely younger than 55 and aged 55 and above, in March and April in the perceived threat, precautions, preparedness, and information accuracy, $X^{2}(9, \mathrm{~N} 1=104, \mathrm{~N} 2=75)=193, \mathrm{p}<0.05$. Older people had a lower perception of threat and preparedness in March compared to the younger age group. They had a significant increase in their perceived threat and preparedness in April.

Similarly, the Chi-Square two-sample test was conducted to examine differences by gender in March and April. The results indicated significant differences between females and males in terms of their perceived threat, precautions, preparedness, and information accuracy in March and April, $X^{2}(9, \mathrm{~N} 1=104, \mathrm{~N} 2=75)=202, \mathrm{p}<.05$. Males had the lowest rating in perceived preparedness in March, which increased significantly in April.

In addition, the Chi-Square two-sample test was conducted to examine differences among the age groups by gender in March and April. The results indicated significant differences between the different age groups by the different genders in terms of their perceived threat, precautions, preparedness, and information accuracy in March and April, $X^{2}(21, \mathrm{~N} 1=104, \mathrm{~N} 2=75)=221, \mathrm{p}<.05$. Male elders had the lowest ratings in the perceived threat and preparedness in March, which increased significantly in April.

Three Chi-Square two-sample tests were also conducted to examine whether there are significant differences in participants' awareness of wearing masks in March and April using their responses to the following three questions: do you wear a face mask so as not to contract the coronavirus, $X^{2}(1, \mathrm{~N} 1=104, \mathrm{~N} 2=75)=0.027$, p >.05; do you think wearing a face mask appropriately can protect yourself from the coronavirus $X^{2}(2, \mathrm{~N} 1=104, \mathrm{~N} 2=75)=1.008$, $\mathrm{p}>.05$; and what face mask do you wear to protect yourself from the coronavirus $X^{2}(4, \mathrm{~N} 1=104, \mathrm{~N} 2=75)=62, \mathrm{p}$ $<.05$. There were no significant differences in March and April surveys regarding wearing a face mask or correctly wearing a face mask to not contract the coronavirus. However, there was a significant difference in what type of face masks to wear to protect themselves from the coronavirus. For the question "what face mask do you wear to protect yourself from the coronavirus," the participants chose the options "N95 filter mask", "surgical mask," "dust mask," "none," and "do not know" at 11, 2, 3, 87, and 1 respectively in the March survey, while the participants' options were $32,7,1,19$, and 15 , respectively in the April survey.

\section{Discussion}

Responses to adverse conditions, such as a pandemic, can be very different in various locations and populations. Jones (2020) noted that in the assessments of how a pandemic unfolded, local circumstances were extremely 
revealing. These assessments reflected that epidemics developed as a social response in multiple phases. The first phase was influenced by the populations' desire for self-reassurance and economic interests and clues were often ignored until increasing levels of illness and deaths forced reluctant acknowledgments of the pandemic. In later phases, increased recognition of the pandemic demanded responding actions, responsibility, and closure. Anthropologists Wilkinson and Fairhead noted that an understanding of local dynamics contributed significantly to communities' reactions and involvements, especially in diverse communities in the United States during epidemics (Closser, 2020). Understanding human behavior was crucial to curbing the transmission of the COVID-19. The increased awareness of measures such as social distancing, isolation, stay-at-home orders, use of face masks, handwashing, and disinfecting surfaces now became the new realities in addressing this pandemic (West, Michie, Rubin, \& Amlot, 2020).

This study provides two snapshots of insights into the sudden changes in early responses to the pandemic among faculty in a southern Texas university setting. During the early stages of the COVID-19 outbreak, this study demonstrated the changing fluctuations between the first phase when clues to the prevalence of the pandemic were just becoming known, which were contrasted to the subsequent phases when the community perceived more preparedness to face and control the pandemic. With an increased awareness of the COVID-19 threat between March and April, most of the respondents were still confident that the U.S. was prepared to control the transmission of the pandemic. Although precautions such as social distancing, isolation, and handwashing were well recognized, the results also indicated that the benefits of mask-wearing were not well understood in both March and April. This could have been one of the potential reasons explaining why there was a subsequent surge in COVID-19 cases and death in May and June 2020 in Southern Texas. The CDC guideline had been acknowledged as the primary information resource. The changing fluctuations between March and April reflected the changes and bias in the CDC guideline and could have explained why there were no significant changes in the awareness of mask-wearing. A lesson learned in these early responses in the pandemic was to encourage the community to implement all potentially effective precaution measures when sufficient evidence was temporarily unavailable, such as mask-wearing, to save lives.

Older people aged 55 and above had significantly lower awareness of the coronavirus threat and preparedness than those under 55 years old in March and may have needed more attention at the very early phase of the pandemic. The World Health Organization (WHO, 2020, April 3) supported these concerns among older populations and noted that those over 55 years old had significantly higher risks of developing severe illness if they contracted the disease because of their potential underlying health conditions, in addition to their aging physiological changes. The CDC (2021) also noted that older adults were at a higher risk of hospitalization for COVID-19. Eight out of ten COVID-19 deaths in the United States were in those populations of adults over 65 years old; therefore, they had a greater risk of death (CDC, 2021).

Men had a lower increase in their perception of COVID-19 threat and preparedness than women between March and April. Men aged 55 and above had the least perceived level of threat and preparedness in March. Older women faced increased risks associated with isolation and its ensuing potential for depression (Prechtl, 2020), but older men were more than twice as likely to die of COVID-19 than older women (Mallapathy, 2020, August 28; Rosenfeld, 2020, April 30; Van Beusekom, 2020, April 29). This risk for men was potentially due to the higher expression of the angiotensin-converting enzyme-2 (ACE-2; receptors for coronavirus) in men, as well as differences in lifestyle, such as higher levels of smoking and drinking among men (Bwire, 2020). The male group needed more health education and health intervention at the early phase of a pandemic.

The COVID-19 pandemic had focused attention on the vital importance of public health, and in multiple realms, this pandemic had changed the world. As knowledge increased about the prevention and treatment of the COVID-19, protocols in public health education and public health policy likewise changed. The pandemic altered the U.S. public health awareness and shifted public health from behind-the-scenes operations to a more prominent focus, with nearly daily announcements and increased knowledge of public health terms such as physical distancing, flattening the curve, contact tracing, and herd immunity becoming part of the common vernacular (Powers, 2020). The pandemic also increased collaboration among the health care community and public health professionals, with more interfaces developed between public health organizations and health care organizations and providers. Additionally, increased knowledge of the impact of the social determinants of health, such as access to care, aging issues, safety-related care, mental health resources, etc. occurred (Robeznieks, 2020; November, 20).

Health education plays an essential role in pandemics. Public behavior such as practicing hygienic guidelines and using appropriate precautions recommended by the CDC helped in slowing down the spread of the virus, and at the 
same time, helped in saving lives. Health education provided information about the emerging pandemic and helped mitigate negative social phenomena such as fear, stigma, and discrimination (Person, Sy, Holton, Govert, \& Liang, 2004). The negative social phenomenon led to the denial of clinical symptoms, refusal to accept reality, delay in reaching out to a health care provider, and increased risk of infection. Better communication of public health education for different groups helped prevent and address social stigma, reduced the spread of a pandemic, and reduced the death rate.

The health education of COVID-19 precautions had prepared the public in terms of social distancing, isolation, stay-at-home orders, use of face masks, hand washing, and disinfecting surfaces to address the spread of COVID-19. The coordination of various public health agencies at the county, state, and federal levels helped provide the public with accurate information at different stages of the pandemic. The collaboration of different agencies also helped provide the required information quickly and appropriately. Decreased perceived information accuracy from March to April indicated that the respondents in this study had more trust in the information posted on social media over time. Health agencies should consider how to use social media more effectively for health education. Health policy also played an important part in preventing the transmission of COVID-19. Federal, state, and local health policies and political orders greatly impacted the isolation of viruses and the production, transportation, and distribution of health personnel and medical equipment, which significantly influenced how society controlled the spread of the COVID-19. When facing a pandemic, both healthcare education and health care policy approaches worked in conjunction were most effective in addressing the containment and the eradication of COVID-19.

\section{Competing Interests Statement}

The authors declare that there are no competing or potential conflicts of interest.

\section{References}

Branswell, H. (2020, April 3). Americans are underestimating how long coronavirus disruptions will last, health experts say. Retrieved from https://www.statnews.com/2020/04/03/americans-are-underestimating-how-long-coronavirus-disruptions-w ill-last-health-experts-say/

Bwire, G. M. (2020). Coronavirus: Why men are more vulnerable to COVID-19 than women? SN Comprehensive Clinical Medicine, 1-3. https://doi.org/10.1007/s42399-020-00341-w

Centers for Disease Control and Prevention. (2021). Coronavirus disease (COVID-19): Guidance for COVID-19. Retrieved from https://www.cdc.gov/coronavirus/2019-ncov/communication/guidance.html

Closser, S. (2020). Addressing resistance to social distancing with compassion, not judgment. Johns Hopkins Medicine. Retrieved from https://www.hopkinsmedicine.org/news/articles/addressing-resistance-to-socialdistancing-with-compassion-not-judgment

Cuomo, A. M. (2020, March 7). No. 202: Declaring a disaster emergency in the state of New York. Retrieved from https://www.governor.ny.gov/news/no-202-declaring-disaster-emergency-state-new-york

Facher, L. (2020). President Trump just declared the coronavirus pandemic a national emergency. Here's what that means. Retrieved from https://www.statnews.com/2020/03/13/national-emergency-coronavirus/

Jones, D. S. (2020). History in a crisis: Lessons for Covid-19. New England Journal of Medicine, 382, 1681-1683. https://doi.org/10.1056/NEJMp2004361

Mallapathy, S. (2020, August 28). The coronavirus is most deadly if you are older and male: New data reveal the risks. Nature. Retrieved from https://www.nature.com/articles/d41586-020-02483-2

Person, B., Sy F., Holton K., Govert B., \& Liang A. (2004), National Center for Infectious Diseases/SARS Community Outreach Team. Emerging Infectious Diseases, 10(2), 358-63.

Prechtl, M. (2020). COVID 19: The impact on older women. Soroptimist International. Retrieved from https://www.soroptimistinternational.org/covid-19-the-impact-on-older-women/

Powers, M. P. (2020). How will COVID-19 reshape future of US public health? Field expected to evolve post-pandemic. The Nation's Health. Retrieved from https://www.thenationshealth.org/content/50/5/1.3

Robeznieks, A. (2020, November 20). COVID-19 is transforming public health. It's not the first time. American Medical Association. Retrieved from https://www.ama-assn.org/delivering-care/health-equity/covid-19transforming-public-health-it-s-not-first-time 
Rosenfeld, S. (2020, April 30). Men twice as likely to die from COVID-19 than women. HCP Live. Retrieved from https://www.hcplive.com/view/men-twice-likely-die-covid-19-women

Stebbens, S. (2020, April 18). Unemployment: These are every state's claims since the coronavirus shut the economy down. Retrieved from https://www.usatoday.com/story/money/2020/04/14/coronavirusunemployment-claims-caused-covid-19-crisis-state/5130034002/

Stieb, M. (2020, April 14). Harvard study: Some social distancing measures may be needed until 2022. Retrieved from https://nymag.com/intelligencer/2020/04/harvard-study-some-social-distancing-required-into2022.html

The New York Times. (2020, March 19). At war with no ammo': Doctors say shortage of protective gear is dire. Retrieved from https://www.nytimes.com/2020/03/19/health/coronavirus-masks-shortage.html

The New York Times. (2020, March 21). Watch how the coronavirus spread across the United States. Retrieved from https://www.nytimes.com/interactive/2020/03/21/us/coronavirus-us-cases-spread. html

The New York Times. (2020, April 18a). Coronavirus Map: Tracking the global outbreak. Retrieved from https://www.nytimes.com/interactive/2020/world/coronavirus-maps.html

The New York Times. (2020, April 18b). Coronavirus in the US: Latest map and case count. Retrieved from https://www.nytimes.com/interactive/2020/us/coronavirus-us-cases.html

USA Today. (2020). COVID-19 restrictions: map of COVID-19 case trends, restrictions and mobility. Retrieved from https://www.usatoday.com/storytelling/coronavirus-reopening-america-map/

Van Beusekom, M. (2020, April 29). Studies find men more prone to COVID-19 death. Centers for Infectious Disease Research and Policy. Retrieved from https://www.cidrap.umn.edu/news-perspective/2020/04/studies-find-men-more-prone-covid-19-death

West, R., Michie, S., Rubin, G. J., \& Amlot, R. (2020). Applying principles of behavior change to reduce SARS-CoV-2 transmission. Nature Human Behavior, 4, 451-459. https://doi.org/10.1038/s41562-020-0887-9

World Health Organization [WHO]. (2020, April 3). WHO delivers advice and support for older people during COVID-19. Retrieved from https://www.who.int/news-room/feature-stories/detail/who-delivers-advice-andsupport-for-older-people-during-covid-19\#: :text=The\%20COVID\%2D19\%20pandemic,potential\%20unde rlying $\% 20$ health $\% 20$ conditions

World Health Organization [WHO]. (2021). WHO Coronavirus (COVID-19) Dashboard. Retrieved from https://covid19.who.int/

\section{Copyrights}

Copyright for this article is retained by the author(s), with first publication rights granted to the journal.

This is an open-access article distributed under the terms and conditions of the Creative Commons Attribution license (http://creativecommons.org/licenses/by/4.0/). 